\title{
Nutrition in pregnant or lactating rats programs lipid metabolism in the offspring
}

\author{
BY A. LUCAS ${ }^{1,2}$, B. A. BAKER ${ }^{1}$, M. DESAI ${ }^{3}$ AND C. N. HALES \\ ${ }^{1} M R C$ Dunn Nutrition Unit, Downham's Lane, Milton Road, Cambridge CB4 1XJ \\ ${ }^{2}$ University Department of Paediatrics, Addenbrooke's Hospital, Cambridge CB2 $2 Q Q$ \\ ${ }^{3}$ Department of Clinical Biochemistry, University of Cambridge, Addenbrooke's Hospital, \\ Hills Road, Cambridge CB2 2QR
}

(Received 20 October 1995 - Revised 7 February 1996-Accepted 16 February 1996)

\begin{abstract}
Epidemiological studies in humans show that size in early life is related to blood cholesterol concentrations in adult life, raising the hypothesis that early nutrition programs later lipid metabolism, affecting risk for later vascular disease. Here, we tested the hypothesis that nutrition during pregnancy or lactation in the rat programs lipid metabolism in the offspring, studied in adult life (mean 6 months). Rats $(n$ 35) from normally-fed dams (controls) were compared with (1) rats $(n 22)$ from dams proteinrestricted in pregnancy and lactation; (2) rats $(n 9)$ born to normally-fed mothers crossed to proteinrestricted lactating dams and (3) those $(n$ 9) born of protein-restricted dams and crossed to normally-fed lactating animals. In these latter three groups the offspring showed long-term reduction in plasma cholesterol, HDL-cholesterol and triacylglycerol concentrations compared with controls. The effects were predominantly in males. These findings suggest that in the rat the sensitive period for nutritional programming of cholesterol and triacylglycerol metabolism is both pre- and postnatal (pre-weaning) and that rats may be 'indirectly' programmed by altering the maternal nutritional milieu during gestation or lactation. Whilst it has been hypothesized that early human undernutrition programs risk for vascular disease, one aspect of undernutrition, low maternal protein intake, in this rat model programmed lower plasma cholesterol and triacylglycerol concentrations.
\end{abstract}

Maternal diet: Lipid metabolism: Nutritional programming

Whether early nutrition has a long-term 'programming' effect (Lucas, 1994) on risk factors for adult degenerative vascular disease is currently an area of major public health concern (Fall et al. 1992). Epidemiological studies in humans show that size in early life is related to adult plasma levels of cholesterol, LDL-cholesterol and apoprotein B, recognized risk factors for cardiovascular disease. Thus weight at 1 year is inversely related to apoprotein B (Barker et al. 1993 b); and subjects who had a small abdominal circumference have the highest levels of total and LDL-cholesterol in adult life (Barker et al. 1993c). In addition, men in the 60's who were breast fed and not weaned by 1 year and those who were bottle fed had higher plasma total and LDL-cholesterol concentrations; the highest values being seen in those heavy at birth and light at 1 year (Barker et al. 1993a). These retrospective epidemiological findings generate the hypothesis that early nutrition has a role in programming long-term lipid metabolism in humans (Hales \& Barker, 1992).

Currently, this hypothesis is being tested prospectively in humans (A. Lucas, R. Morley and $\mathbf{M}$. Fewtrell, unpublished results). However, studies in animal models are important in defining effective nutritional interventions, sensitive periods and fundamental mechanisms for such programming events. In the early 1970s, Hahn (1984) reduced litter size in rats to induce experimental overfeeding during the sucking period: rats from small litters (four 
pups) had, in adult life, a permanent elevation in total plasma cholesterol concentration compared with values found in adult rats from normal litters (fourteen pups). Mott $e t$ al. (1991) assigned baboons to breast or formula feeding and at the end of infancy fed both groups on a 'Western'-style, high-saturated-fatty-acid diet. Compared with those fed on formula, the previously breast-fed group, in adult life, had higher serum levels of LDL- and VLDL-cholesterol, lower values of HDL-cholesterol, greater absorption of cholesterol from the gut, lower cholesterol excretion and, at post mortem, significantly more atherosclerosis (Lewis et al. 1988). These two examples in animal models provide compelling experimental evidence that adult cholesterol metabolism may be programmed by early nutrition.

In the animal studies cited the early dietary manipulation was applied to the infant. There has been speculation in humans however, (Hales \& Barker, 1992) that nutrition of the mother could program long-term health outcomes in her progeny. In the current study we tested the hypothesis in an established rat model (Snoeck, 1990; Dahri et al. 1993; Desai et al. 1995) that maternal nutrition (low protein intake), either in pregnancy or lactation, could have a permanent programming effect on circulating lipids in the offspring.

\section{METHODS}

The methods used have been described in detail by Desai et al. (1996). Briefly, virgin female Wistar rats, weighing 240-260 g, were mated with normal males. Day 0 of gestation was taken as the day on which vaginal plugs were expelled. The rats were either fed on a diet containing $200 \mathrm{~g}$ protein $/ \mathrm{kg}$ ('regular' diet) or an isoenergetic diet containing $80 \mathrm{~g}$ protein $/ \mathrm{kg}$ ("low-protein' diet) throughout pregnancy and lactation. The diet was purchased from Hoppe Farms BV, Hoge Rijndijk 14, 3440 HD Woerden, The Netherlands. Details of the diets are available from the manufacturers and summarized elsewhere (Desai et al. 1996). These diets are identical to those used by Snoeck et al. (1990). Casein was used as the protein source. The $80 \mathrm{~g}$ protein $/ \mathrm{kg}$ diet was made isoenergetic using cerelose (glucose) and its fat content was similar to the $200 \mathrm{~g}$ protein $/ \mathrm{kg}$ diet.

Spontaneous delivery took place on day 22 of gestation. Feeding an $80 \mathrm{~g}$ protein $/ \mathrm{kg}$ diet to pregnant rats did not have any adverse effects on the ability of the dams to carry litters, nor was perinatal mortality changed (Desai et al. 1996). Pregnant rats fed on an $80 \mathrm{~g}$ protein $/ \mathrm{kg}$ diet showed a decreased gain in total body weight with no significant differences in total feed intake and litter size when compared with the pregnant rats fed on a $200 \mathrm{~g}$ protein $/ \mathrm{kg}$ diet (Desai et al. 1996).

After birth, at $3 \mathrm{~d}$ of age, large litters were reduced to eight pups, ensuring a standard litter size per dam. Thus each mother nursed a total of eight pups, four males and four females. At $21 \mathrm{~d}$ of age two males and two females were studied for other variables and the remaining offspring were followed into adult life. A large random subsample of these latter animals was included in the current study on the early dietary effects on blood lipids. Four groups were followed into adult life. The two main groups were as follows: group 1 (controls) comprised thirty-five pups from ten dams that received the regular, $200 \mathrm{~g}$ protein $/ \mathrm{kg}$ chow during both pregnancy and lactation; group 2 (low protein group) comprised twenty-two pups from seven dams that received the low-protein $(80 \mathrm{~g} / \mathrm{kg}) \mathrm{chow}$ during pregnancy and lactation. Two smaller crossover groups were designed as follows: group 3 (postnatal low protein group) comprised nine pups born of three pregnant dams fed on a regular $200 \mathrm{~g}$ protein $/ \mathrm{kg}$ diet that were the suckled by the dams fed on the lowprotein diet throughout gestation and lactation, and group 4 (prenatal low protein group) comprised nine pups born to three dams on a low protein $(80 \mathrm{~g} / \mathrm{kg})$ diet and then suckled by the dams fed on the regular $200 \mathrm{~g}$ protein $/ \mathrm{kg}$ diet throughout. From $21 \mathrm{~d}$ the offspring 
were weaned onto a normal laboratory chow (LAD 1: Rat and Mouse Breeder Diet, Special Diet Services, Witham, Essex). They continued on this diet into adulthood.

The present paper focuses solely on the impact of early nutrition on long-term lipid metabolism. However, the nutritional interventions affected other outcomes including early and later growth as reported by Desai et al. (1996). Briefly, since handling pups immediately after birth was found, in a pilot study, to cause loss of pups (resulting from mothers eating their pups or refusal to nurse them), the first body weights were recorded at $3 \mathrm{~d}$ of age to avoid undue stress to the mothers and pups. These weights were significantly different between groups 1 and $2(9.3$ (SD 1.4) and 6.2 (SD 0.8) g respectively $P<0.001$ ). Animals from groups 2 and 3 continued to have lower body weights than group 1 (controls) even as adults despite weaning them onto a normal laboratory chow (LAD1 containing $200 \mathrm{~g}$ protein $/ \mathrm{kg}$ ). Their feed intake was also lower than that of group 1 .

All animal work was undertaken with appropriate approval and in accordance with Home Office regulations. For analytical purposes, groups 2-4 were each compared separately with the controls, and also combined to produce a 'pre- or postnatal low protein group' ( $n 40)$ for comparison with controls ( $n$ 35). Statistical analyses included ANOVA, Student's $t$ tests and regression analysis.

\section{Blood samples and assays}

Blood samples from the offspring were taken from the tail, by amputation of the tip, at a mean of 6 months of age (184 (SD 50) d). Samples were separated, the plasma stored at $-85^{\circ}$ and subsequently analysed for total cholesterol, HDL-cholesterol and triacylglycerols. The assays were done on a Roche 'Cobas Bio' centrifugal analyser using Roche kits (Roche Diagnostics, Welwyn Garden City, Herts.). Instrument precision tests were made before each batch of analyses. The instrument coefficients of variation were $0 \cdot 3-0 \cdot 5 \%$.

Triacylglycerols were analysed by an enzymic colorimetric test with glycerol phosphate oxidase $(E C 1.1 .3 .21)$ and 4-aminophenazone. Plasma triacylglycerols were converted to glycerol by lipoprotein lipase $(E C 3.1 .1 .34)$. The glycerol was converted to glycerol-3phosphate by glycerol kinase (EC 2.7.1.30) and then to dihydroxyacetone phosphate and $\mathrm{H}_{2} \mathrm{O}_{2}$ which, in the presence of peroxidase (EC 1.11.1.7), effects the oxidative coupling of 4-chloriphenol and 4-aminophenazone to form a red-coloured quinoneimine derivative. The colour intensity, determined at a wavelength of $520 \mathrm{~nm}$, is proportional to triacylglycerol concentration.

Total cholesterol was analysed by an enzymic colorimetric test. Cholesterol ester was converted to cholesterol by cholesterol esterase (EC 3.1.1.13) and thence to 4-cholesten3-one and $\mathrm{H}_{2} \mathrm{O}_{2}$ by cholesterol oxidase ( $E C$ 1.1.3.6). Liberated $\mathrm{H}_{2} \mathrm{O}_{2}$ in the presence of peroxidase effects the oxidative coupling of phenol and 4-aminoantipyrine to form a redcoloured quinoneimine derivative. The colour intensity, determined at a wavelength of $500 \mathrm{~nm}$, is directly related to cholesterol concentration.

LDL and VLDL were precipitated using a phosphotungstate- $\mathrm{MgCl}_{2}$ reagent. After centrifugation at $4000 \mathrm{rev} . / \mathrm{min}$ for $10 \mathrm{~min}$, the HDL remains in the supernatant fraction. HDL-cholesterol was then assayed enzymically as described for cholesterol.

Quality control sera ('Precinorm' supplied by Boehringer Mannheim UK, Diagnostics and Biochemistry Ltd, Lewes, E. Sussex) were included with each batch of samples. Interassay coefficients of variation were all below $2 \%$. 


\section{RESULTS}

\section{Main comparison}

The two main groups (group 1: controls; group 2: maternal low protein intake during pregnancy and lactation) were sampled at corresponding ages in adult life. Group means for plasma lipids are compared in Fig. 1; there were significantly lower values in rats from mothers given low-protein $v$. control diets for plasma cholesterol; control $v$. low protein $(\mathrm{mmol} / \mathrm{l}): 2.20 \mathrm{SE} 0.19)$ v. $1.69(\mathrm{sE} 0.10), 95 \%$ CI $0.09-0.93 \quad(P=0.019)$; for HDLcholesterol: 1.88 (SE 0.19) v. 1.43 (SE 0.32), $95 \%$ CI $0.05-0.85(P=0.029)$; and for plasma triacylglycerol: 2.95 (SE 0.34) v. 1.70 (SE 0.17), $95 \%$ CI 0.48-2.01 (P=0.002).

\section{Analyses including crossover groups}

Fig. 1 also shows group means for the two further crossover groups: group 3, postnatal low protein group (rats who were fed by mothers who received the low-protein diet in lactation) and group 4, the prenatal low protein group (rats born to dams given low protein in pregnancy). ANOVA for each lipid type showed significant differences between the four comparison groups, reflecting the higher values in the controls. Indeed, there were no significant differences between groups 2,3 and 4, suggesting that giving dams a low-protein diet postnatally (group 3), prenatally (group 4) or both (group 2) had the same impact on plasma cholesterol, HDL-cholesterol and triacylglycerol concentrations in the offspring. Despite the small sample size, compared with controls (using Student's $t$ test) the postnatal low protein group (group 3 ) had significantly lower plasma cholesterol $(P=0.04)$, HDLcholesterol $(P=0.05)$ and triacylglycerol $(P=0.004)$ concentrations. Results for group 4 (prenatal low protein) had a larger standard deviation, and a significant reduction compared with controls was only found for triacylglycerol $(P=0.03)$.

\section{Combined groups}

Since lipid values for groups 2,3 and 4 did not differ, they were combined and compared with those in group 1 (controls) (Fig. 1). The reductions in plasma cholesterol, HDLcholesterol and triacylglycerol concentrations in this combined group were again significant compared with controls $(P=0.02, P=0.03$ and $P=0.0006$ respectively). All these differences between groups and combined groups observed were also found after adjusting for minor chance differences between groups in age at blood sampling.

\section{Influence of sex}

Table 1 shows that males had significantly higher plasma cholesterol and triacylglycerol concentrations than females $(P=0.04$ and $P=0.001$ respectively) and a trend to higher values of HDL-cholesterol $(P=0.09)$.

Analyses were performed to explore whether the maternal dietary effect on the offspring was influenced by their sex. For these analyses group 1 (control group) was compared with three reduced maternal protein intake groups (2, 3 and 4) combined, as described previously. Table 1 shows that the maternal dietary effect on plasma cholesterol and HDLcholesterol in the offspring was only seen in males. Whilst the dietary effect was significant for plasma triacylglycerol in both males and females, there was a greater effect in males. Indeed there was a significantly greater effect of diet in males than females (interaction between sex and diet) for HDL-cholesterol $(P=0.03)$ and some evidence for this interaction for total cholesterol $(P=0.09)$ and triacylglycerol $(P=0.09)$. The interaction between sex and diet justifies analysing the data according to sex. 



Fig. 1. Plasma cholesterol, HDL-cholesterol and triacylglycerol concentrations in adult rats (mean age 6 months) from dams fed on the following diets: (1) $200 \mathrm{~g}$ protein $/ \mathrm{kg}$ in maternal diet (control group); (2) $80 \mathrm{~g} \mathrm{protein} / \mathrm{kg}$ in maternal diet during gestation and lactation (low protein group); (3) $200 \mathrm{~g}$ protein $/ \mathrm{kg}$ in maternal diet during gestation and $80 \mathrm{~g}$ protein $/ \mathrm{kg}$ in maternal diet during lactation (postnatal low protein group); (4) $80 \mathrm{~g} \mathrm{protein} / \mathrm{kg}$ in maternal diet during gestation and $200 \mathrm{~g}$ protein $/ \mathrm{kg}$ in maternal diet during lactation (prenatal low protein group). The mean values for groups 2,3 and 4 combined are also given. Values are means for thirty-five (group 1), twenty-two (group 2), nine (groups 3 and 4) and forty (groups 2, 3 and 4 combined) rats, with their standard errors represented by vertical bars. Mean values were significantly different from controls: ${ }^{*} P<0.05,{ }^{* *} P<0.01$, $* * * P<0.001$.

\section{DISCUSSION}

The present study shows that, in the rat, maternal nutrition in pregnancy and lactation has a long-term programming effect on lipid metabolism in the offspring. Dams given a lowprotein diet $(80 \mathrm{~g} / \mathrm{kg}$ chow) in both pregnancy and lactation had offspring that in adult life (mean 6 months) had significant reductions in plasma concentrations of cholesterol, HDL- 


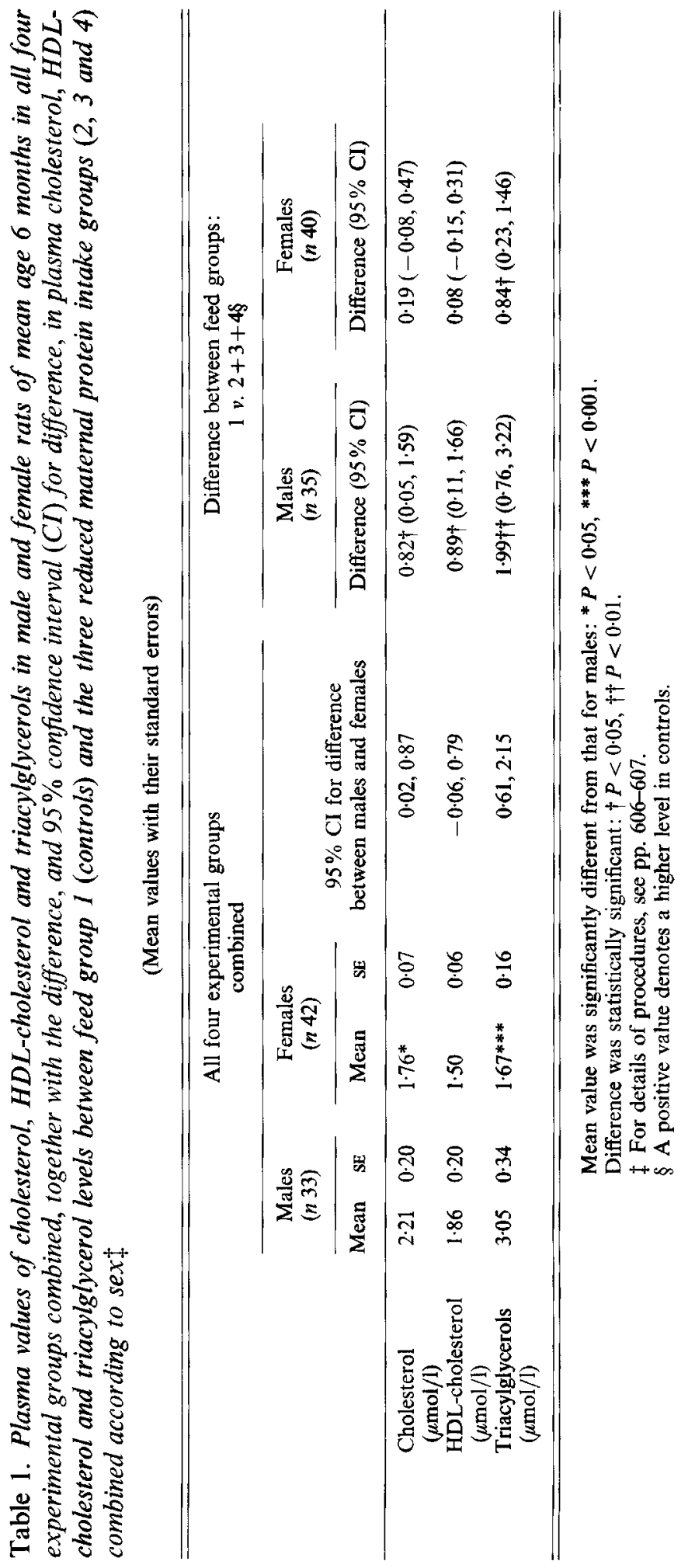


cholesterol and triacylglycerols compared with those of controls. Whether this programming effect was due to pre- or postnatal dietary manipulation was explored in two smaller crossover groups in which the progeny of dams fed on regular $200 \mathrm{~g}$ protein $/ \mathrm{kg}$ chow were suckled by dams fed on an $80 \mathrm{~g}$ protein $/ \mathrm{kg}$ chow (postnatal low protein group) and vice versa (prenatal low protein group). In these groups, plasma values of the three lipids in the progeny were low and similar to those of the progeny of dams who received the low-protein diet during both pregnancy and lactation, providing evidence that, in the rat, the critical period for long-term programming of lipid metabolism extends from fetal life into the sucking period.

We chose a low-protein dietary intervention because use of this model had proven successful in demonstrating programming, in the offspring, of insulin secretion and diabetic tendency (Snoeck et al. 1990), blood pressure (Langley-Evans et al. 1994), and obesity (Anguita et al. 1993). It might be argued that this model has limited application to humans in whom isolated protein deficiency would be uncommon. However, the present study supports the general concept that, in rats at least, manipulation of the nutritional milieu of the fetus and suckled animal could have lifelong effects. It remains important to dissect which specific classes of nutrients are critical in the programming process, and further nutrients are now being investigated. We emphasize that the present study explores the impact of specific nutritional intervention in the dam. We recognize that protein deficiency in the dam could affect availability of many other nutrients (i.e. cause more general undernutrition) in the fetus or sucking animal; we are currently exploring this.

The observed interaction between sex and diet is of wider biological interest in relation to the hitherto unexplained increased vulnerability to early nutrition of males (Smart, 1977; Lucas et al. 1990). For instance, using the same model, Anguita et al. (1993) showed a diet-sex interaction in relation to the development of obesity and Desai et al. (1996) showed such an interaction in relation to growth and development of specific organs, notably muscle and pancreas. Possibly nutritional sensitivity in the male relates to the faster growth of tissues and hence more critical nutritional needs; or perhaps additional genetic material on the second $\mathrm{X}$-chromosome has protective value in the female.

Our observation that cholesterol and triacylglycerol metabolism may be programmed in both fetal and sucking animal suggests that in each case the initial programming trigger(s) may be effective when received either by intravascular (transplacental) or enteral route. The lifetime programming of lipid metabolism after a brief early dietary manipulation leaves intriguing questions about the underlying mechanisms. Which organs or organ systems are programmed? Where does the 'memory' of the early nutritional event reside, given repeated cell replacement during life? Could the initial event be a programmed change in gene expression, clonal selection within developing tissues or differential proliferation of cell lines with different metabolic functions (Lucas, 1994; Desai et al. 1995). Our further work focuses on these issues.

Our original intention was to test the hypothesis, generated by human epidemiological work (Fall et al. 1992), that early malnutrition might program later risk of vascular disease, including elevated plasma cholesterol concentrations. We have apparently shown the opposite; plasma cholesterol was reduced in the offspring of protein-undernourished dams. Our findings, however, are consistent with those of Hahn (1984), who showed that overnutrition in neonatal rats, achieved by reducing litter size during suckling, was associated with long-term elevation of total cholesterol in plasma. Thus, in both studies, the less nourished group had lower plasma cholesterol later in life. Using a similar but not identical rat model to ours, Langley-Evans et al. (1994) found that early maternal malnutrition programmed higher blood pressure in the offspring; but in our experiments on the same animals studied here we found the opposite (results not shown), in parallel with our findings here on cholesterol. 
Whilst we have not, therefore, provided direct support for this early malnutrition hypothesis in humans, our findings do at least implicate early nutrition in long-term programming of factors which would be cardiovascular risk markers in man. Our long-term clinical prospective studies in which we have applied randomized early nutritional interventions will eventually provide direct evidence on nutritional programming of cardiovascular disease in humans (Lucas et al. 1990; Lucas \& Morley, 1994). We suggest, however, that use of this rat model could be of value in providing insights into the mechanisms of nutritional programming of cardiovascular risk factors and may point to future pertinent clinical studies.

We wish to thank the animal house staff at the MRC Dunn Nutrition Unit, Cambridge, for their invaluable assistance and Mrs Evelyn Smith for preparing the manuscript.

\section{REFERENCES}

Anguita, R. M., Sigulem, D. M. \& Sawaya, L. (1993). Intrauterine food restriction is associated with obesity in young rats. Journal of Nutrition 123, 1421-1428.

Barker, D. J. P., Gluckman, P. D., Godfrey, K. M., Harding, J. E., Owens, J. A. \& Robinson, J. S. (1993a). Fetal nutrition and cardiovascular disease in adult life. Lancet 341, 938-941.

Barker, D. J. P., Hales, C. N., Fall, C. H. D., Osmond, C., Phipps, K. \& Clark, P. M. S. (1993b). Type 2 (noninsulin-dependent) diabetes mellitus, hypertension and hyperlipidaemia (syndrome $\mathrm{X}$ ): relation to reduced fetal growth. Diabetologia 36, 62-67.

Barker, D. J. P., Martyn, C. N., Osmond, C., Hales, C. N. \& Fall, C. H. D. (1993c). Growth in utero and serum cholesterol concentrations in adult life. British Medical Journal 307, 1524-1527.

Dahri, S., Snoeck, A., Reusens-Billin, B., Remacle, C. \& Hoet, J. J. (1993). Low protein diet during gestation in rats: its relevance to human non insulin dependent diabetes. Journal of Physiology 467, 292.

Desai, M., Crowther, N. J., Lucas, A. \& Hales, C. N. (1996), Organ-selective growth changes in the offspring of protein-restricted mothers. British Journal of Nutrition 76, 591-608.

Desai, M., Crowther, N. J., Ozanne, S. E., Lucas, A. \& Hales, C. N. (1995). Adult glucose and lipid metabolism may be programmed during fetal life. Biochemical Society Transactions 23, 331-335.

Fall, C. H. D., Barker, D. J. P., Osmond, C., Winter, P. D., Clark, P. M. S. \& Hales, C. N. (1992). Relation of infant feeding to adult serum cholesterol concentration and death from ischaemic heart disease. British Medical Journal 304, 801-805.

Hahn, P. (1984). Effect of litter size on plasma cholesterol and insulin and some liver and adipose tissue enzymes in adult rodents. Journal of Nutrition 114, 1231-1234.

Hales, C. N. \& Barker, D. J. P. (1992). Type 2 (non-insulin-dependent) diabetes mellitus: the thrifty phenotype hypothesis. Diabetologia 35, 595-601.

Langley-Evans, S. C., Phillips, G. J. \& Jackson, A. A. (1994). In utero exposure to maternal low protein diets induces hypertension in weaning rats, independently of maternal blood pressure changes. Clinical Nutrition 13, 319-324.

Lewis, D. S., Mott, G. E., McMahon, C. A., Masoro, J., Carey, K. D. \& McGill, H. C. (1988). Deferred effects of preweaning diet on atherosclerosis in adolescent baboons. Atherosclerosis 8, 275-280.

Lucas, A. (1994). Role of nutritional programming in determining adult morbidity. Archives of Disease in Childhood 71, 288-290.

Lucas, A. \& Morley, R. (1994). Does early nutrition program later blood pressure? British Medical Journal 309, 304-308.

Lucas, A., Morley, R., Cole, T. J., Gore, S. M., Lucas, P. J., Crowle, P., Pearse, R., Boon, A. J. \& Powell, R. (1990). Early diet in preterm babies and developmental status at 18 months. Lancet 335, 1477-1481.

Mott, G. E., Lewis, D. S. \& McGill, H. C. (1991). Programming of cholesterol metabolism by breast or formula feeding. In The Childhood Environment and Adult Disease. CIBA Foundation Symposium 156, pp. 56-76 [G. R. Bock and J. Whelan, editors]. Chichester: Wiley.

Smart, J. L. (1977). Early life malnutrition and later learning ability - critical analysis. In Genetics, Environment and Intelligence, pp. 215-235 [A. Olivero, editor]. Amsterdam: Elsevier.

Snoeck, A., Remacle, C., Reusens-Billen, G. \& Hoet, J. J. (1990). Effect of a low protein diet during pregnancy on the fetal rat-endocrine pancreas. Biology of the Neonate 57, 107-118. 